\title{
Systematic Literature Review of Crime Prediction and Data Mining
}

\author{
Adesola Falade*, Ambrose Azeta, Aderonke Oni, Isaac Odun-ayo \\ Department of Computer and Information and Information Sciences, Covenant University, Ota, Ogun State, Nigeria
}

Corresponding Author Email: adesola.falade@ covenantuniversity.edu.ng

https://doi.org/10.18280/rces.060302

Received: 12 June 2019

Accepted: 26 August 2019

\section{Keywords:}

FIRs-first information report, CCTVclosed circuit television, IB-Intelligence Bureau, NCB-Narcotics Control Bureau, SVM-support vector machine, DNN-deep neural network, ML-machine learning, NoSQL-no structured query language

\begin{abstract}
Crime is a social menace that impacts negatively on social economic development of a nation. Crime has been in existence from time immemorial and violent crime is the main enemy of the society. One of the primary responsibilities of any government is security of life and properties which translates to reduction of crime rate and provisioning of adequate security to its citizenry. To this end, government must wake up to its responsibilities by reducing crime rate and provide adequate security to its citizenry through effective, efficient and proactive policing. Any research in this direction that can help in analyzing and predicting the future occurrence of violent crime by using crime dataset is laudable. Predicting future occurrence of crime from crime dataset is well reported in literature, therefore it has become imperative to come up with an overview of the present state of the art on crime prediction and control.

The systematic review present in this study focuses on crime prediction and data mining as well as the techniques employed in the past studies. The existing work is classified and grouped into different categories and are presented by using visualization approach. It is found that more studies adopted supervised learning approaches to crime prediction and control compared to other methods. The challenges encountered were also reported. Crime prediction has become hot research area in recent time because of its intending benefits to socio-economic development of a nation.
\end{abstract}

\section{INTRODUCTION}

Crime can be described as a cankerworm that negatively impact on social and economic development of any nation. In an area where crime is endemic, no development can take place [1]. Individual and nation are retrogressively affected by this monster called crime. However, it is the responsibility of any government to provide a secured environment for its citizenry. Several researches have gone into crime prediction, prevention and control in the past, all in an effort to facilitate the implementation of an efficient and effective predictive policing. Police and other law enforcement agency are the custodian of past crime records and they maintained the crime database [2-4]. Data obtained from this source should be analyzed to gain useful insights and knowledge to assist in decision making process. Numerous studies in the past have reported a number of techniques for analyzing crime data among which are statistical and machine learning techniques [3]. Therefore crime data analytics can provide information about crime statistics and report for a region or country [4]. Thus this will be useful to law enforcement agencies for aiding in proactive decision making in order to provide adequate security and safety for their citizenry [5]. Crime prediction and data mining information may be of different types and can be seen as categorized in Figure 1.

\section{MOTIVATION AND OBJECTIVES}

The main motivation of this study is to explore the various crime prediction and data mining techniques and challenges reported in literature as well as to know which state of the arts are relevant. The analysis in the study will offer knowledge to other researchers in knowing which categories of crime prediction and data mining measures and techniques as well as challenges that have been covered in the previous research studies and also help to identify gaps. The objectives of the study are to systematically review crime prediction and data mining approaches, issues and challenges faced in the existing studies. This review will help researchers gain state of the arts methods of crime prediction and data mining and more so help highlighting research gaps.

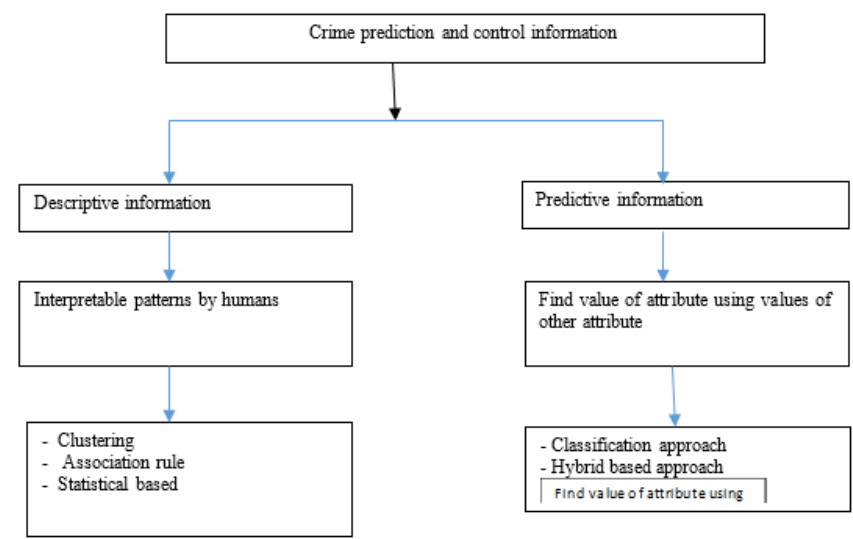

Figure 1. Crime prediction and data mining information categories

The rest of the paper is organized as follows: Research 
methodology used for the study is described in Section two, while classification of crime prediction and crime data analyses is presented in Section three using the following criteria: (1) Techniques used. (2) Technologies used and (3) various challenges addressed. Sources of crime dataset and types of crime is discussed in section four. Result of the review is discussed in section five, while conclusion and future directions is presented in section six.

\section{RESEARCH METHODOLOGY}

The methodology employed in this study is composed of three steps. The first step involves getting related research work in crime prediction and data mining. The second step involves establishing a classification scheme illustrated in Section three. Presentation of the summary of findings and report of detailed literature review is the third step. The following research questions will be investigated:

RQ1: What are the different techniques used in crime prediction and crime data mining? To provide answer to this question, bar chart in section three explain and illustrate frequency of publications corresponding to different techniques in this area.

RQ2: What are the various techniques and measures used in crime prediction and data mining? To be able to answer this question, Table four in Section three described the techniques used in crime prediction and data mining.

RQ3: What are the various challenges involved in crime prediction and data mining. In providing answer to this question, pie chart in section three describes the various challenges and issues faced.

\subsection{Screening \& search strategy}

In choosing relevant articles for this study, five major databases were selected. For this purpose, these major databases of electronic journals were searched. The following are the digital libraries considered:

-IEEE Xplore (http://ieeexplore.ieee.org),

-ACM Digital Library (www.acm.org/dl)

-Science Direct (http://www.sciencedirect.com),

- Springer (http://www.springerlink.com),

-Wiley Inter science (http://www.interscience.wiley.org).

Study Selection: Journal published research papers, conference proceedings and workshops which are thought to be worthy of consideration are used for the study. Keyword based search is used to pick the most relevant work. The keywords used are: violent crime prediction and data mining. Those that are not directly related to crime prediction and data mining were discarded. Omission of any research paper was based on the following criteria:

- Research paper that have not been published, nonEnglish related papers, text-books, Master and Doctoral dissertations, and papers that are not peer-reviewed.

- Crime prediction and data mining researches published between 2004 and 2018 which are current and recent were considered. The search strategies and the number of outcomes obtained is presented in Table 1. Some of the studies which are not relevant are excluded from the returned studies. The abstract of articles returned during search which could not be estimated based on titles were considered. After reading such papers, if the abstract is not evident, the paper is considered irrelevant and then excluded. it.

Table 1. Search selection criteria used

\begin{tabular}{|c|c|c|c|c|c|c|c|}
\hline \multirow[t]{2}{*}{ Sno } & \multirow[t]{2}{*}{ E-resources } & \multirow{2}{*}{$\begin{array}{c}\text { Studies } \\
\text { returned }\end{array}$} & \multicolumn{3}{|c|}{ Excluded } & \multirow{2}{*}{$\begin{array}{c}\text { Keywords } \\
\text { used }\end{array}$} & \multirow{2}{*}{$\begin{array}{c}\text { Studies } \\
\text { repeated }\end{array}$} \\
\hline & & & Base on title & Base on abstract & base on full text & & \\
\hline \multirow[t]{2}{*}{1} & \multirow[t]{2}{*}{ http://ieeexplore.ieee.org } & 10 & 1 & 3 & - & $\begin{array}{c}\text { crime } \\
\text { prediction }\end{array}$ & \multirow[t]{2}{*}{7} \\
\hline & & 12 & 2 & 1 & - & $\begin{array}{c}\text { crime data } \\
\text { analysis }\end{array}$ & \\
\hline \multirow[t]{2}{*}{2} & \multirow[t]{2}{*}{ http://www.acm.org } & 5 & 3 & 1 & - & $\begin{array}{c}\text { crime } \\
\text { prediction }\end{array}$ & \multirow[t]{2}{*}{-} \\
\hline & & 1 & - & - & - & $\begin{array}{c}\text { crime data } \\
\text { analysis }\end{array}$ & \\
\hline \multirow[t]{2}{*}{3} & \multirow[t]{2}{*}{ www.sciencedirect.com } & 13 & 4 & 2 & 3 & $\begin{array}{c}\text { crime } \\
\text { prediction }\end{array}$ & \multirow[t]{2}{*}{3} \\
\hline & & 29 & 12 & 6 & 4 & $\begin{array}{c}\text { crime data } \\
\text { analysis }\end{array}$ & \\
\hline \multirow[t]{2}{*}{4} & \multirow[t]{2}{*}{ www.springerlink.com } & 73 & 38 & 14 & 13 & $\begin{array}{c}\text { crime } \\
\text { prediction }\end{array}$ & \multirow[t]{2}{*}{8} \\
\hline & & 27 & 10 & 7 & 4 & $\begin{array}{c}\text { crime data } \\
\text { analysis }\end{array}$ & \\
\hline \multirow[t]{2}{*}{5} & \multirow[t]{2}{*}{ www.interscience.wiley.com } & 9 & 2 & 1 & 2 & $\begin{array}{c}\text { crime } \\
\text { prediction }\end{array}$ & \multirow[t]{2}{*}{6} \\
\hline & & 18 & 10 & 3 & 3 & $\begin{array}{c}\text { crime data } \\
\text { analysis }\end{array}$ & \\
\hline
\end{tabular}

\subsection{Classification scheme establishment}

The chosen selection process used for this study resulted in 225 papers altogether, eliminating papers repeated from five different digital libraries on 30th November 2018, 12.30 PM. The papers were carefully classified and accessed and were further classified in accordance with the criteria formulated in section 2 of this paper.

\subsection{Papers distribution and summary of researches in crime prediction}

The results obtained after classification proffer important guidelines for future research direction on crime prediction and data mining. The number of related literature to crime prediction and data mining has increased enormously. Papers from 2004 to 2018 were reviewed. These papers and their 
distribution over the years are presented in Table 2. Also presented in Table 6 is the summary of the researches in crime prediction and data mining according to the contribution of the past studies.

Table 2. Distribution of papers over the years

\begin{tabular}{|c|c|c|c|c|c|c|c|c|c|c|c|c|c|c|}
\hline Year & 2004 & 2006 & 2007 & 2008 & 2009 & 2010 & 2011 & 2012 & 2013 & 2014 & 2015 & 2016 & 2017 & 2018 \\
\cline { 1 - 10 } e-Resources & & & & & & & & & & & & & & \\
\hline IEEE & 1 & & 1 & 1 & 1 & 1 & 2 & 1 & 1 & 3 & 2 & 1 & 1 & \\
\hline ACM & & & 1 & & & & 1 & 1 & & 1 & 1 & 1 & 2 & \\
\hline Science direct & & 1 & & & 1 & 1 & 2 & 1 & 1 & 2 & 2 & 2 & 2 & \\
\hline Springer & & 1 & 1 & & & 1 & 1 & & & 2 & & & & \\
\hline e-print & & & & & & & 1 & & & & & & 1 & 1 \\
\hline
\end{tabular}

\section{CLASSIFICATION METHOD}

Different The following criteria are used to classify the research papers:

(1) Techniques used, (2) Technologies used and (3) Gaps and issues addressed.

\subsection{Classifications based on the techniques used}

The information on Table 3 shows the crime prediction's various techniques applied on the basis of papers reviewed. The various corresponding techniques used along with frequency of publications in crime prediction and data mining are illustrated using a bar chart in Figure 2.

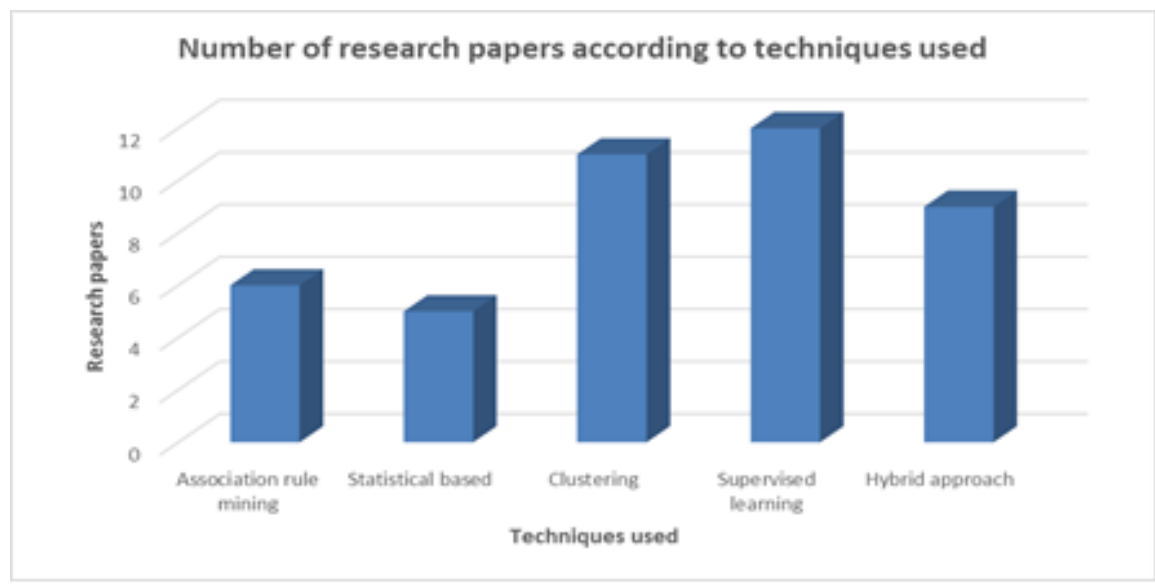

Figure 2. Number of research papers according to techniques used

Table 3. Various crime prediction and mining techniques used

\begin{tabular}{|c|c|}
\hline Technique & Description \\
\hline Clustering & $\begin{array}{l}\text { - Process of grouping similar objects//data into classes of similar objects. } \\
\text {-A cluster identified from data objects can be treated as one group. }\end{array}$ \\
\hline Classification & $\begin{array}{l}\text { - Sample inputs and outputs are used as example to classify and predict unknown } \\
\text { data. } \\
\text { - Model is derived to determine the class of an object based on its attributes. }\end{array}$ \\
\hline Association rule mining & $\begin{array}{l}\text { - Relationship between variables and data objects are sought. } \\
\text { - A well research method and popular for discovering interesting relationships } \\
\text { between variables in large databases. }\end{array}$ \\
\hline Frequent pattern mining & $\begin{array}{l}\text { - Use to find frequent patterns that occur in a dataset. } \\
\text { - It is the foundation for finding inbuilt regularities in data. }\end{array}$ \\
\hline Hybrid a & $\begin{array}{l}\text { - Combining two or more supervised learning methods together for the purpose of } \\
\text { crime prediction. }\end{array}$ \\
\hline Outlier analysis & $\begin{array}{l}\text { - Identify items or events, or specific observations that is not in-line with an } \\
\text { expected pattern. } \\
\text { - It is also called the process of detecting anomalies in data. }\end{array}$ \\
\hline Regression analysis & $\begin{array}{l}\text { - Most cases use to predict range of numeric data values (continuous values), from } \\
\text { a particular dataset. }\end{array}$ \\
\hline
\end{tabular}

\subsection{Classifications based on the challenges addressed}

The gaps found and addressed in the papers reviewed were applied as the third classification criteria. Difficulty in data collection, data preprocessing, data storage, performance and integration are mostly discussed [6-8]. Other issues addressed involved dealing with data that does not have specified structure, selection of appropriate methods, selection of appropriate technologies and collection of data from reliable sources [9-11]. The various gaps addressed by various research papers are presented using a pie-chart in Figure 3. 


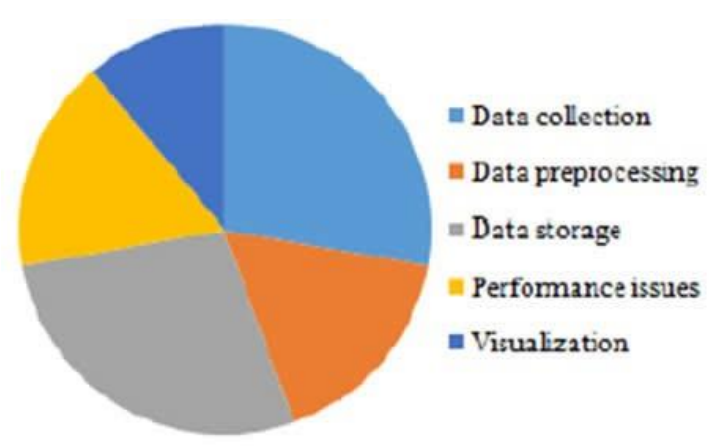

Figure 3. Challenges addressed by the research papers

\subsubsection{Data collection and integration}

Input process is critical in the crime prediction and control process $[9,11]$. Data pertaining to crime is collected from various heterogeneous sources such as criminal records, social media, news, and police reports (FIRs) etc. Collecting such a huge volume of data is highly challenging, according to [12].

\subsubsection{Data preprocessing}

The data about crime collected are usually in various formats such as text, images, graph, audio, relational data, unstructured datand semi-structured data [13]. According to [14], the process of transforming these various data in different formats to the understandable and desired format is a major challenge in crime prediction.

\subsubsection{Data storage issues}

Data associated with crime is characterized by huge amount of data. Crime prediction requires a large amount of storage and this necessitate a new data management technique located on distributed processing systems [15]. New database technology NoSQL such as Apache Hadoop is becoming a new standard for crime prediction and data analytics [16].

\subsubsection{Performance related issues}

Issues bordering on performance are usually concerned with processing time, reliability and precision [17-19]. Technologies and techniques used affect the processing time. In resolving this problem, there is need to evolve algorithms and technologies to increase the precision and accuracy.

\subsubsection{Issues on visualization}

Visualizing the results from crime prediction and crime data analysis is a major challenge [11]. Knowledge representation using bar-charts, graphs, and pie-chart is often referred to as visualization [20]. It is in most cases difficult to lay hands on a user-friendly visualization for the massive data [20].

\section{CRIME SOURCES AND TYPES}

Discovering a successful investigation and the right insights, it becomes very important to recognize the available data sources of crime and the various types of crime [21].

\subsection{Crime data sources and analysis}

Report from the Police and other law enforcement agencies were discovered. Crime report from Police FIRs
(First Information Report) archives historical crime data that contain important information about crime, complainants and the suspects.

First Information Report (FIRs) made by the police from the victim are normally written by police staff on paper and usually in an unstructured format. This is one of the reliable ways of crime data collection [22].

\subsection{Investigation files}

The police use previous investigation files of the suspect to identify a previously convicted suspect, these files are usually in text, photo, credit card statements, CCTV video files, phone call, bank account, e-mail send \& receive records, forensic reports, witness \& victim statements and lawyer statements $[23,24]$.

\subsection{Intelligence reports}

Data and information about criminals are usually maintained by intelligent agencies. National Intelligence Agencies (NIA) of Nigeria, Intelligence Bureau (IB), and Narcotics Control Bureau (NCB) are some of these agencies $[25,26]$.

\subsection{Intelligence findings}

Intelligence findings that are open source based are extracted from the web, search engines, and social media platforms such as (Facebook, Twitter, and LinkedIn). This information is highly in an unstructured format [27, 28].

\subsection{Police records}

Criminal suspects and their records are usually maintained by police officers for future references and use. These records are kept in relational data format or text format [29].

\subsection{Type of crimes}

Different crime categories are presented in Table 5, which are classified by various law-enforcement agencies. Different types of crime, such as arm robbery and kidnapping concern police at various divisions and levels of government [27, 30]. Other types of crime such as cybercrimes and terrorism are usually investigated by local, national and international agencies [31].

\section{RESULTS}

This systematic review brings together the evidence for the collection of data used for crime prediction and control in Nigeria. A total of 42 studies were included in the review. Out of this total, six (6) used Association rule mining for crime pattern analysis from crime data. The limitation of this approach is processing time and visualization were not considered. Five (5) other studies applied statistical based techniques such as Principal Component Analysis, Spatial Statistics Analysis for crime prediction. The result obtained were inefficient and inaccurate as it takes time to make crime prediction. Eleven (11) out of the reviewed studies applied Clustering approach to crime prediction where it produces unreliable prediction result with noisy data and when the 
number of clusters are small. Thirteen (13) concentrated on supervised learning techniques where some of the authors use Frequent pattern mining, emotion mining, Support Vector Machine, Decision Tree and Neural Network techniques on crime data. Some of these techniques have some inherent deficiencies that really affected the output and performance of the model developed. For example, decision tree is prone to over-fitting when dataset is huge and also deep neural network will produce inaccurate results when dataset is small. Lastly, only seven (7) researchers adopted hybrid approach for crime prediction and data mining and only five out these actually focused on spatio-temporal crime prediction. Some of the authors that applied hybrid approaches to crime prediction and data mining problem, use association rule mining and Genetic Algorithms, while some of authors applied IF-IDF and Bayesian Network while some also applied K-means and Deep Neural Network. But some noticeable gap in all of these is that there is an appreciable reduction in the overall performance of the system when dataset become huge. Some studies used demographic and social media data for their crime prediction while in some other studies, historical crime data was used for prediction the occurrence of crime. The summary of the review result is presented in Table 4.

Table 4. Technologies used in crime prediction and data mining

\begin{tabular}{|c|c|c|}
\hline $\begin{array}{l}\text { Technology } \\
\text { used }\end{array}$ & Description of technology & Technology features \\
\hline SPSS & $\begin{array}{c}\text { - Acronym is for Statistical Package for Social Sciences } \\
\text { - Can handle and process highly complex data manipulation } \\
\text { and analysis }\end{array}$ & $\begin{array}{l}\text { - Can assign names and labels to variables and data } \\
\text { values } \\
\text { - Missing data codes can easily be defined } \\
\text { - Ability to read a wide variety of data formats such as } \\
\text { binary, numeric, alphanumeric and time format } \\
\text { - Ability to read non-rectangular and hierarchical raw } \\
\text { data files } \\
\text { - Ability to read and write to compressed data files }\end{array}$ \\
\hline MongoDB & $\begin{array}{l}\text { - supports both NoSQL database and JSON- like document } \\
\text { technology for dynamic schemas }\end{array}$ & $\begin{array}{l}\text {-uses ad hoc queries } \\
\text {-indexing based } \\
\text {-support replication } \\
\text {-can aggregate } \\
\text { - have load balancing } \\
\text { - support file storage } \\
\end{array}$ \\
\hline $\mathrm{Neo} 4 \mathrm{j}$ & $\begin{array}{l}\text { - supports ACID - compliant database technology with both } \\
\text { processing and native graph memory }\end{array}$ & $\begin{array}{c}\text {-have easy query language } \\
\text {-support indexing } \\
\text {-support unique constraints } \\
\text {-represents semi-structured data easily }\end{array}$ \\
\hline ESOM tool & $\begin{array}{c}\text { - Ability to perform data mining tasks with Emergent Self- } \\
\text { Organizing Maps (ESOM) }\end{array}$ & $\begin{array}{c}\text {-support visualized animations } \\
\text { - support automated application to new data and creation } \\
\text { of the ESOM classifier }\end{array}$ \\
\hline Weka & $\begin{array}{l}\text { - It has provision for machine learning algorithms and data } \\
\text { mining tasks }\end{array}$ & $\begin{array}{l}\text { - preprocessing of data } \\
\text { - data classification } \\
\text { - clustering of data } \\
\text { - regression analysis } \\
\text { - association rules mining } \\
\text { - results visualizations }\end{array}$ \\
\hline Pig & $\begin{array}{l}\text { - supports high level mechanism for parallel programming of } \\
\text { MapReduce jobs meant to execute on Hadoop clusters. }\end{array}$ & $\begin{array}{c}\text { - complex codes not available } \\
\text { - It supports multi-query approach } \\
\text { - supports SQL-like language such as PigLatin }\end{array}$ \\
\hline Hadoop & $\begin{array}{l}\text { - it forms core component of any state of the art architecture } \\
\text { - allows organizations to store and collect, then analyze and } \\
\text { manipulate large amount of data }\end{array}$ & $\begin{array}{c}\text { - It has ability to handle data in different formats whether } \\
\text { structured, semi structured or unstructured format. } \\
\text { - Plus powerful visualizations }\end{array}$ \\
\hline
\end{tabular}

\section{DISCUSSION}

This systematic literature review is put together from 42 publications. The summary of the researches done in crime prediction and data mining is presented in the Table 5. It all shows that the techniques such as statistical methods, clustering, association rule mining, classification and hybrid approaches can be applied for crime prediction and data mining problem. It is worthy of note that Figure 4 depicted highest number of research papers adopted supervised learning approach with $31 \%$ of the total studies to crime prediction, and this is followed by Clustering with $26 \%$, Hybrid approach with $22 \%$, Association rule mining with $14 \%$ and the least which is statistical based approach with $7 \%$ respectively. Various studies affirmed that application of crime prediction and data mining techniques is majorly dependent on situation available and objectives involved.

Table 5. Research summary of crime prediction and data mining

\begin{tabular}{|c|c|c|c|}
\hline Researchers & Method used & Tasks & Gaps \\
\hline$[9,12,14,15,31,32,33]$ & Association rule mining & $\begin{array}{c}\text { Crime pattern analysis } \\
\text { from crime data }\end{array}$ & $\begin{array}{c}\text { Model's processing time and } \\
\text { visualization were not considered. }\end{array}$ \\
\hline
\end{tabular}




\begin{tabular}{|c|c|c|c|}
\hline$[1,2,10,17,27,35]$ & Statistical based & $\begin{array}{c}\text { Analysis of the similar } \\
\text { crime data }\end{array}$ & $\begin{array}{c}\text { Data collection not available and } \\
\text { no concern with solving } \\
\text { processing time }\end{array}$ \\
\hline $\begin{array}{c}{[3,14,15,17,18,24,25,} \\
31,33,34]\end{array}$ & Clustering & $\begin{array}{c}\text { Data groupings into } \\
\text { similarities and clusters }\end{array}$ & $\begin{array}{c}\text { Produces unreliable results with } \\
\text { noisy data and when number of } \\
\text { clusters are small. }\end{array}$ \\
\hline $\begin{array}{c}{[11,16,17,18,19,23,} \\
25,27,36,37,38,42,43, \\
45]\end{array}$ & Supervised learning & $\begin{array}{c}\text { Crime data analysis and } \\
\text { classification }\end{array}$ & $\begin{array}{c}\text { Accuracy of prediction and } \\
\text { efficiency of the model were not } \\
\text { considered. }\end{array}$ \\
\hline $\begin{array}{c}{[4,6,8,10,22,26,33,} \\
39,40,41,44]\end{array}$ & Hybrid approaches & $\begin{array}{c}\text { Relational patterns } \\
\text { among crime locations } \\
\text { and crime were exploited } \\
\text { and use to build crime } \\
\text { prediction models }\end{array}$ & $\begin{array}{c}\text { Crime types and time slots for } \\
\text { crime occurrence could not be } \\
\text { predicted by the model. Also } \\
\text { crime prediction is near } \\
\text { impossible when there is no } \\
\text { sufficient data to feed the model. }\end{array}$ \\
\hline
\end{tabular}

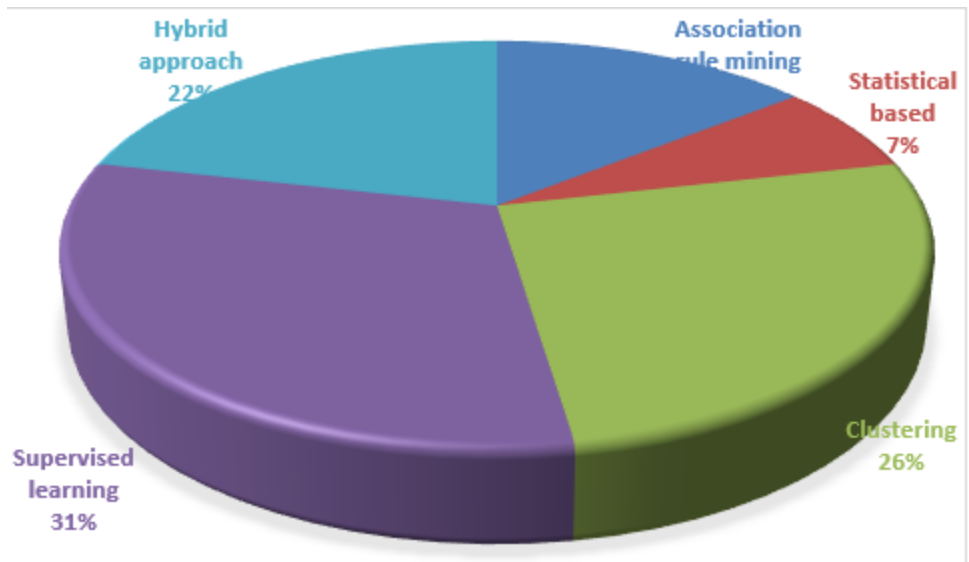

Figure 4. Summary of findings

\section{CONCLUSION}

Crime prediction and data mining has become hot research areas in recent time because of its attendance benefits to socio-economic development of a nation. Outcome of this research will definitely benefit and help potential researchers to have good understanding of the available and the state of the arts techniques for crime prediction and control. The analytics of crime prediction and data mining can be used to give statistical reporting of crime in a particular area or region. This will ultimately benefit the society by making law enforcement agency and the government understand the various factors and causes of crime. Hence agencies of government can take a better and proactive decision towards improving the safety of the citizens.

\section{ACKNOWLEDGMENT}

This is to acknowledge the financial support of Center for ICT/ICE Research, known as Covenant University Centre for Research, Innovation and Discovery (CUCRID), Ota, Nigeria.

\section{REFERENCES}

[1] Gok, M., Celik, A., Ozal, Y., Ozgul, F. (2012). Mining hate crimes to figure out reasons behind. IEEE/ACM International Conference on Advances in Social Networks Analysis and Mining, Istanbul, Turkey, pp. 887-889. https://doi.org/10.1109/ASONAM.2012.159

[2] Chung, W., Xu, J.J., Wang, G., Qin, Y., Chau, M., Chen,
H. (2004). Crime data mining: A general framework and some examples. Computer, IEEE, 37(4): 50-56. https://doi.org/10.1109/MC.2004.1297301

[3] Chen, Y.F., Huang, H., Ma, L.H. (2010). AK-modes: A weighted clustering algorithm for finding similar case subsets. 2010 IEEE International Conference on Intelligent Systems and Knowledge Engineering, Hangzhou, China, pp. 218-223. https://doi.org/10.1109/ISKE.2010.5680876

[4] Atzenbeck, C., Celik, A., Erdem, Z., Ozgul, F. (2011). Incorporating data sources and methodologies for crime data mining. Proceedings of 2011 IEEE International Conference on Intelligence and Security Informatics, pp 176-180. https://doi.org/10.1109/ISI.2011.5983995

[5] Adesola, F., Misra, S., Omoregbe, N., Damasevicius, R., Maskeliunas, R. (2019). An IOT-Based Architecture for Crime Management in Nigeria. In: R. K. Shukla et al. (eds) Springer Nature Singapore Pte Ltd.

[6] Li, C.T., Jeng, S.K., Huang, Y.Y. (2015). Mining location-based social networks for criminal activity prediction. Wireless and Optical Communication Conference (WOCC), IEEE, pp. 185-189. https://doi.org/10.1109/WOCC.2015.7346202

[7] Ahishakiye, E., Opiyo, E. D. Taremwa, D., Niyonzima, I. (2017). Crime prediction using decision tree (J48) classification algorithm. International Journal of Computer and Information Technology, 6(3).

[8] Wang, B., Zhang, D.H., Brantingham, P.J., Bertozzi, A.L. (2017). Deep learning for real time crime forecasting. eprint arXiv:1707.03340, NOLTA, 2017arXiv170703340W.

[9] Gifford, C.M., Buczak, A.L. (2010). Fuzzy association 
rule mining for community crime pattern discovery. ISIKDD, Washington D.C, U.S.A, ACM, pp. 1-10. https://doi.org/10.1145/1938606.1938608

[10] Ester, M., Glasser, U., Brantingham, P.L., Tayebi, M.A. (2014). CRIMETRACER: Activity space based crime location prediction. IEEE/ACM International Conference on Advances in Social Networks Analysis and Mining (ASONAM 2014), Beijing, China, pp. 472480. https://doi.org/10.1109/ASONAM.2014.6921628

[11] Chang, K.C., Hsing, T.P., Chou, S., Chen, P.S. (2006). Mining criminal databases to finding investigation clues-by example of stolen automobiles database. Intelligence and Security Informatics, pp. 91-102. https://doi.org/10.1007/11734628_12

[12] Elzinga, P., Viaene, S., Van Hulle, M.M., Dedene, G., Poelmans, J. (2009). Gaining insight in domestic violence with emergent self-organizing maps. Expert Systems with Applications, 36(9): 11864-11874. https://doi.org/10.1016/j.eswa.2009.04.027

[13] Lee, I., Phillips, P. (2011). Crime analysis through spatial areal aggregated density patterns. Geoinformatica, 15(1): 49-74. https://doi.org/10.1007/s10707-010-0116-1

[14] Bagula, A., Berman, S., Isafiadea, O. (2015). A revised frequent pattern model for crime situation recognition based on floor-ceil quartile function. Procedia Computer Science, 55: 251-260. https://doi.org/10.1016/j.procs.2015.07.042

[15] Corcoran, J., Higgs, G., Brunsdon, C. (2007). Visualising space and time in crime patterns: A comparison of methods. Computers, Environment and Urban Systems, 31(1): 52-75. https://doi.org/10.1016/j.compenvurbsys.2005.07.009

[16] Oh, G.S., Paek, S.Y., Park, H.H. (2012). Measuring the crime displacement and diffusion of benefit effects of open-street CCTV in South Korea. International Journal of Law, Crime and Justice, 40(3): 179-191. https://doi.org/10.1016/j.ijlcj.2012.03.003

[17] Javideh, M., Ebrahimi, M.R., Keyvanpour, M.R. (2011). Detecting and investigating crime by means of data mining: A general crime matching framework. Procedia $\begin{array}{lll}\text { Computer } \quad \text { Science, } & 3 \text { : } & \text { 872-880. }\end{array}$ https://doi.org/10.1016/j.procs.2010.12.143

[18] Leroy, G., Ku, C.H. (2014). A decision support system: Automated crime report analysis and classification for e-government. Government Information Quarterly, 31(4):

534-544. https://doi.org/10.1016/j.giq.2014.08.003

[19] Bhatnagar, V., Jain, A. (2016). Crime data analysis using pig with Hadoop. Procedia Computer Science, 78: 571- 578. https://doi.org/10.1016/j.procs.2016.02.104

[20] Li, X.G., Juhola, M. (2014). Country crime analysis using the self-organizing map with special regard to demographic factors. Springer, AI \& Soc, 29(1): 53-68. https://doi.org/10.1007/s00146-013-0441-7

[21] Erdem, Z., Bowerman, C., Bondy, B., Ozgul, F. (2010). Combined detection model for criminal network detection. PAISI, Springer, pp. 1-14. https://doi.org/10.1007/978-3-642-13601-6_1

[22] Yan, Q.B., Zhang, L., Peng, L.Z., Han, H.B., Chen, Z.X. (2015). Using map-based interactive interface for understanding and characterizing crime data in cities. ICSI-CCI, Springer, pp. 479-490. https://doi.org/10.1007/978-3-319-20469-7_51
[23] Gupta, M., Gupta, M.P., Chandra, B. (2007). Adaptive query interface for mining crime data. DNIS, Springer, pp. 285-296.

[24] Lee, I., Phillips, P. (2012). Mining co-distribution patterns for large crime datasets. Expert Systems with Applications, $39(14)$ : 11556-11563. https://doi.org/10.1016/j.eswa.2012.03.071

[25] Jain, A., Arora, S., Agarwal, S., Gupta, T., Tyagi, N., Tayal, D.K. (2015). Crime detection and criminal identification in India using data mining techniques. Springer, AI \& Soc, 30(1): 117-127. https://doi.org/10.1007/s00146-014-0539-6

[26] Evans, M., Kang, J., Mohan, P., Shekhar, S. (2011). Identifying patterns inspatial information: A survey of methods. Wiley Online Library, 1(3): 193-214. https://doi.org/10.1002/widm.25

[27] Huang, X., Silva, E., Ghodsi, M., Hassani, H. (2016). A review of data mining applications in crime. Statistical Analysis and Data Mining: The ASA Data Science Journal, 9(3): 139-154. https://doi.org/10.1002/sam.11312

[28] Ewart, B., Oatley, G. (2011). Data mining and crime analysis. Wiley Online Library, 1(2): 147-153. https://doi.org/10.1002/widm.6

[29] Quick, M., Chan, P.W., Law, J. (2014). Analyzing hotspots of crime using a Bayesian spatiotemporal modeling approach: A case study of violent crime in the greater Toronto area. Geographical Analysis, 47(1): 119. https://doi.org/10.1111/gean.12047

[30] Leroy, G., Ku, J. (2011). A crime reports analysis system to identify related crimes. Journal of the American Society for Information Science and Technology, 62(8): 1533-1547. http://doi.org/10.1002/asi.21552

[31] Xu, J.J., Chen, H.C., Chau, M., Schroeder, J. (2007). Automated criminal link analysis based on domain knowledge. Journal of the American Society for Information Science and Technology, 58(6): 842-855. http://doi.org/10.1002/asi.20552

[32] Packer, M.W., Thomason, M.B., Wesley, J.C., Hansen, P.J., Conklin, J.H., Brown, D.E., Lyons, A.M. (2006). Uniform crime report "super clean" data cleaning tool. Proceedings of the 2006 Systems and Information Engineering Design Symposium, Charlottesville, VA, USA, pp. 14-18. http://doi.org/10.1109/SIEDS.2006.278706

[33] Lee, I., Phillips, P. (2009). Criminal cross correlation mining and visualization. PAISI, Springer, pp. 2-13. https://doi.org/10.1007/978-3-642-01393-5_2

[34] Kang, H.W., Kang H.B. (2017). Prediction of crime occurrence from multi-modal data using deep learning. PLoS ONE, 12(4): https://doi.org/10.1371/journal.pone.0176244

[35] Yang, D.Q., Heaney, T., Tonon, A., Cudre-Mauroux, P. (2017). CrimeTelescope: Crime hotspot prediction based on urban and social media data fusion. World Wide Web, 21(5): 1323-1347. https://doi.org/10.1007/s11280-017-0515-4

[36] Abdul, A., Jakaria, R., Imran, R. (2017). Using data mining technique to analyze crime of Bangladesh. IJCSN-International Journal of Computer Science and Network, 6(4): 489-494.

[37] Gulumbe, S.U., Dikko, H.G., Bello, Y. (2014). Analysis of crime data using principal component analysis: A 
case study of Katsina State. CBN Journal of Applied Statistics, 3(2): 39-49.

[38] Srisuk, S., Thongtae, P. (2008). An analysis of data mining applications in crime domain. 2008 IEEE 8th International Conference on Computer and Information Technology Workshops, Sydney, QLD, Australia, pp. 122-126. https://doi.org/10.1109/CIT.2008.Workshops.80

[39] Usha, D., Rameshkumar, K. (2014). Application of frequent pattern mining and association rule mining on crime pattern mining. Journal of Advances in Computer Science and Technology, 3(4): 264-275.

[40] Waduge, N., Ranathunga, L. (2017). Machine learning approaches for detecting crime patterns. https://www.reseachgate.net/publication/319465093, accessed on 16 April 2019.

[41] Devan, M.S., Gangadharan. S., Sathyadevan, S. (2014). Crime analysis and prediction using data mining. in 2014 First International Conference on Networks \& Soft Computing, Guntur, India, pp. 406-412. https://doi.org/10.1109/CNSC.2014.6906719

[42] Jabar, E.K., Hashem, S.H., Hessian, E.M. (2013). Propose data mining AR-GA model to advance crime analysis. IOSR Journal of Computer Engineering
(IOSR-JCE),

14(5):

$38-45$.

https://doi.org/10.9790/0661-1453845

[43] Jeon, J., Jeong, S. (2016). Designing a crime-prevention system by converging big data and IoT. Journal of Internet Computing and Services (JICS), 17(3): 115-128. https://doi.org/10.7472/jksii.2016.17.3.115

[44] Byun, J.Y., Nasridinov, A., Park, Y.H. (2014). Internet of things for smart crime detection. Contemporary Engineering $\quad$ Sciences, 7(15): 749-754. http://dx.doi.org/10.12988/ces.2014.4685

[45] Moona, T., Heoa, S., Leeb, S. (2014). Ubiquitous crime prevention system (UCPS) for a safer city. Procedia Environmental Sciences, 22: 288-301. https://doi.org/10.1016/j.proenv.2014.11.028

[46] Reddy, P., Rajesh, D. (2016). A data analytics applied for crime identification over IOT. International Journal of Science and Research (IJSR), 5(2): 243-246.

[47] Ristea, A., Leitner, M. (2018). Integration of social media in spatial crime analysis and prediction models for events. AGILE 2018 - Lund, June 12-15.

[48] Bao, F., Lu, C.T., Chen, I.R., Shah, S. Crowdsafe: crowd sourcing of crime incidents and safe. in ACM SIGSPATIAL GIS'11, Chicago, IL, USA, ACM, pp. 521-524. https://doi.org/10.1145/2093973.2094064 